\title{
Multi-proxy, localised reconstructions of climate and weathering from cave speleothem samples
}

CHRISTOPHER DAY ${ }^{1}$, FRANZISKA LECHLEITNER ${ }^{2}$ AND PHILIP A E POGGE VON STRANDMANN ${ }^{3}$

${ }^{1}$ University of Oxford

${ }^{2}$ University of Bern

${ }^{3}$ Johannes Gutenberg University

Presenting Author: chris.day@earth.ox.ac.uk

Speleothems (secondary calcium carbonate formations) offer significant potential for recording environmental processes above caves, an area increasingly referred to as the Critical Zone. Speleothems grow for hundreds to millions of years, with absolute chronology from U-Th and U-Pb chronometers. Rainwater infiltrating the soil and flowing down through the cave responds to environmental processes. These complex environmental signals can be preserved within speleothem carbonates. Recent efforts to calibrate, model and interpret this complex geochemistry has progressed along multiple paths. Here we bring together recent examples, including: i) calibrating and using $\mathrm{Li}$ isotopes for reconstructing weathering intensity [1,2]; ii) the use of $\mathrm{Ca}$ isotopes for reconstructing changes in rainfall amount [3]; iii) the combined use of $\mathrm{d}^{13} \mathrm{C},{ }^{14} \mathrm{C}$ and $\mathrm{d}^{44} \mathrm{Ca}$ to demonstrate changes in soil respiration [4]; iv) phasehomogenization micro-thermometry for absolute temperature [5]. In future years, combining these proxies provides the potential of regional-scale input into climate, weathering and the chemical cycling of elements, on timescales from thousands to millions of years.

[1] C.C. Day et al. In press. Lithium isotopes and partition coefficients in inorganic carbonates: proxy calibration for weathering reconstruction. Geochimica et Cosmochimica Acta. [2] P.A.E. Pogge von Strandmann et al. 2017. Lithium isotopes in speleothems: Temperature-controlled variation in silicate weathering during glacial cycles. Earth and Planetary Science Letters. 469, 64-74. [3] R.A. Owen et al. 2016. Calcium isotopes in caves as a proxy for aridity: Modern calibration and application to the $8.2 \mathrm{kyr}$ event. Earth and Planetary Science Letters, 443, 129-138. [4] F.A. Lechleitner et al. (in review). Stalagmite carbon isotopes suggest deglacial increase in soil respiration in Western Europe driven by temperature change. Climate of the Past. [5] A.N. Meckler et al. 2015 Glacialinterglacial temperature change in the tropical West Pacific: A comparison of stalagmite-based paleo-thermometers. Quaternary Science Reviews. 127, 90-116. 